\title{
Gerakan sadar lingkungan melalui sosialisasi dan pelatihan pengelolaan limbah cair rumah tangga dukuh jongso
}

\author{
Erika Rian Prahastiwi ${ }^{*}{ }^{11}$, Eny Wiwin Kartikaningsih ${ }^{2}$, Khoirunnisa $^{2}$, Danang Puji Atmojo ${ }^{3}$, \\ Nira Fery Thania ${ }^{3}$, Adinda Natasya Ayodya ${ }^{4}$ \\ ${ }^{1}$ Program Studi Kimia, Fakultas Matematika dan Ilmu Pengetahuan Alam, Universitas Negeri Semarang, Indonesia \\ ${ }^{2}$ Program Studi Manajemen Pemasaran, Manajemen, Fakultas Ekonomi, Universitas Negeri Semarang, Indonesia \\ ${ }^{3}$ Program Studi Ilmu Politik, Fakultas Ilmu Sosial, Universitas Negeri Semarang, Indonesia \\ ${ }^{4}$ Program Studi Ekonomi Pembangunan, Fakultas Ekonomi, Universitas Negeri Semarang, Indonesia
}

\section{Article Info \\ Article history: \\ Received May $21^{\text {th }}, 2021$ \\ Revised Jun $23^{\text {th }}, 2021$ \\ Accepted Jul 30 ${ }^{\text {th }}, 2021$}

\section{Keyword:}

Household liquid waste

management

Alum

Audio-visual media

\begin{abstract}
Community activities during the pandemic due to the stay at home policy resulted in an increase in the remaining results of activities. As a result, untreated household wastewater will have a negative impact on the surrounding waters and can become a source of disease for the community. The main purpose of this service is to educate and provide skills to the community to treat household wastewater in Jongso Hamlet, Wotan Village. The main material used for wastewater treatment is alum. This is because alum is a coagulant that can bind impurities in water. This service activity is carried out by socializing through online audio-visual media, namely Youtube, while the training is carried out directly at the stage of processing household liquid waste to the Dukuh Jongso community, and activity evaluation indicators are based on participant responses to socialization and training. The results of the implementation showed that the participants were enthusiastic in the socialization and training. This activity is also effective in educating the public, especially about public awareness of the surrounding environment. It is hoped that the community will continue to be committed to improving their knowledge and skills in protecting the surrounding environment. The community care movement for the surrounding environment is expected to continue to be applied independently and disseminated to other communities.
\end{abstract}

(C) 2021 The Authors. Published by IICET.

This is an open access article under the CC BY-NC-SA license (https://creativecommons.org/licenses/by-nc-sa/4.0

\section{Corresponding Author:}

Prahastiwi, E. R.,

$\risingdotseq$ erikarianp@students.unnes.ac.id

\section{Pendahuluan}

Dukuh Jongso Desa Wotan merupakan desa yang terletak di Kabupaten Pati yang memiliki jumlah penduduk \pm 1500 kartu keluarga. Kepadatan penduduk mengakibatkan aktivitas masyarakat semakin banyak, selain itu pandemi covid-19 dengan adanya kebijakan bahwa masyarakat untuk selalu tetap dirumah saja mengakibatkan keterbatas untuk bekerja diluar sehingga aktivitas rumah semakin meningkat (Tuwu, 2020). Meningkatnya aktivitas masyarakat sebanding dengan meningkatnya hasil sisa kegiatan (Kusumawardhani et al., 2017). 
Salah satu sisa aktivitas masyarakat yaitu limbah cair yang berasal dari limbah cair sisa dari kegiatan rumah tangga. Limbah cair rumah tangga yang tidak dikelola akan mengakibatkan dampak negatif bagi perairan di lingkungan sekitar sehingga berakibat pada terganggunya kebutuhan air bersih. Untuk itu perlunya mendapat perhatian untuk penanganannya (Nasihah et al., 2018). Air buangan yang berasal dari rumah tangga (dosmetic waster water), yaitu air limbah yang berasal dari permukiman penduduk, pada umumnya air limbah ini terdiri dari tinja, air bekas cucian dan air dari kamar mandi, yang terdiri dari bahan organik (Dahruji et al., 2017). Dimana kuantitasnya 50- 70\% dari rata-rata pemakaian air bersih sekitar 120-140 liter per orang per hari (Nababan et al., 2020).

Semakin tinggi limbah rumah tangga (dosmetic waster water) dapat menyebabkan timbulnya berbagai penyakit menular. Limbah rumah tangga merupakan sumber mikroba pencemar penyebab berbagai penyakit dan sangat berpotensi menjadi sumber penularan penyakit oleh patogen yang dibawa melalui air. Limbah cair rumah tangga harus diolah terlebih dahulu sebelum dibuang ke lingkungan sehingga tidak menimbulkan dampak negatif terhadap kesehatan masyarakat dan lingkungan (Waluyo, 2017).

Pada umumnya, air limbah rumah tangga di Indonesia relatif belum terjangkau oleh teknologi pengolahan limbah, serta mahalnya biaya teknologi limbah yang ada, sehingga diperlukan sistem pengolahan limbah rumah tangga yang murah dan mudah diterapkan, dan dapat memberi hasil optimal (Nilasari et al., 2016).

Zat pencemar yang terkandung di dalam limbah cair pada umumnya berupa zat padat tersuspensi dan koloid yang bersifat stabil sehingga sulit untuk mengendap. Hal tersebut akibat adanya gaya tolak menolak antara partikel koloid yang bermuatan negatif sehingga tidak dapat membentuk gumpalan. Penambahan koagulan akan menyebabkan destabilisasi partikel-partikel koloid sehingga menyebabkan terjadinya gaya tarik menarik elektrostatis sehingga membentuk gumpalan yang dapat mengendap dengan adanya gaya gravitasi. Tawas merupakan koagulan yang banyak digunakan karena ekonomis, mudah diperoleh di pasaran serta mudah penyimpanannya, selain itu tawas juga mampu mengendapkan zat-zat organik yang relatif cepat (Nurlina et al., 2015). Tawas mudah didapatkan di pasaran bebas dan sering digunakan dalam proses pengolahan air. Selain itu juga banyaknya penelitian sebelumnya menunjukkan bahwa tawas dapat menurunkan pencemaran dalam limbah cair (Nugti et al., 2020).

Masyarakat yang cenderung kurang peduli dan tidak tahunya akan kandungan dari limbah cair mengakibatkan sebagian dari mereka merasa kurang peduli. Oleh karena itu, sangat pentingnya adanya pelatihan pengelolaan limbah guna menjaga lingkungan agar tetap sehat. Dengan pelatihan (training) dimaksudkan untuk melatih dan mengembangkan potensi atau skill masyarakat (Weol, 2015).

\section{Metode}

Sebelumnya pengabdi melakukan pengamatan dilingkungan sekitar tentang tingkat kesadaran masyarakat terhadap lingkungannya. Kemudian mencari solusi kegiatan untuk penanganan masalah dan perencanaan kegiatannya. Sehingga dilakukan kegiatan pengabdian secara online dan langsung dengan beberapa tahapan. Pelaksanaan kegiatan pengabdian kepada masyarakat diselenggarakan secara online melalui media sosial Youtube dan WhatsApp, sedangkan secara langsung dilaksanakan di Dukuh Jongso, Desa Wotan, Kecamatan Sukolilo Kabupaten Pati. Kegiatan secara langsung diikuti oleh beberapa warga. Evaluasi kegiatan ini yaitu aspek pengetahuan dan keterampilan yang dapat disampaikan melalui Google Forms. Media sosial adalah sarana yang merupakan medium berbasis teknologi internet (media Online) yang memungkinkan seseorang dapat berinteraksi sosial, berkomunikasi dan berkerjasama dengan orang lainnya. (Ratnamulyani, 2018: 156).

Pengabdian pertama yang dilakukan secara langsung, dengan tahapan yang pertama melakukan percobaan pengolahan limbah secara mandiri oleh pengabdi dengan mempersiapkan alat bahan yang digunakan dan melakukan pengolahan limbah cair sesuai dengan tahapan-tahapannya, kedua mengumpulkan hasil dokumentasi kemudian mengeditnya menjadi sebuah video yang utuh sesuai tahapan pengolahan limbah cair dan mengupload video di media sosial Youtube, ketiga membagikan link melalui grup WhatsApp Pemberdayaan Kesejahteraan Keluarga (PKK), dan evaluasi dilakukan melalui Google Forms yang telah dibuat dan dibagikan di grup. Indikator dari keberhasilan metode ini dievalusi berdasarkan keantusiasan jumlah responden yang didata melalui Google Forms.

Pengabdian kedua yang dilakukan secara langsung dirumah pengabdi, dengan tahapan pertama memberikan informasi kepada masyarakat bahwa akan diadakan pelatihan pengolahan limbah cair, kedua mempersiapkan alat bahan dan sampel yang akan digunakan, ketiga melakukan pelatihan dan memberikan penjelasan tentang pengetahuan limbah dan pengolahannya, dan melakukan evaluasi dengan 
mendengarkan pendapat dari peserta yang mengukuti pelatihan. Indikator dari keberhasilan metode ini dievalusi berdasarkan keantusiasan peserta berdasarkan data kualitatif.

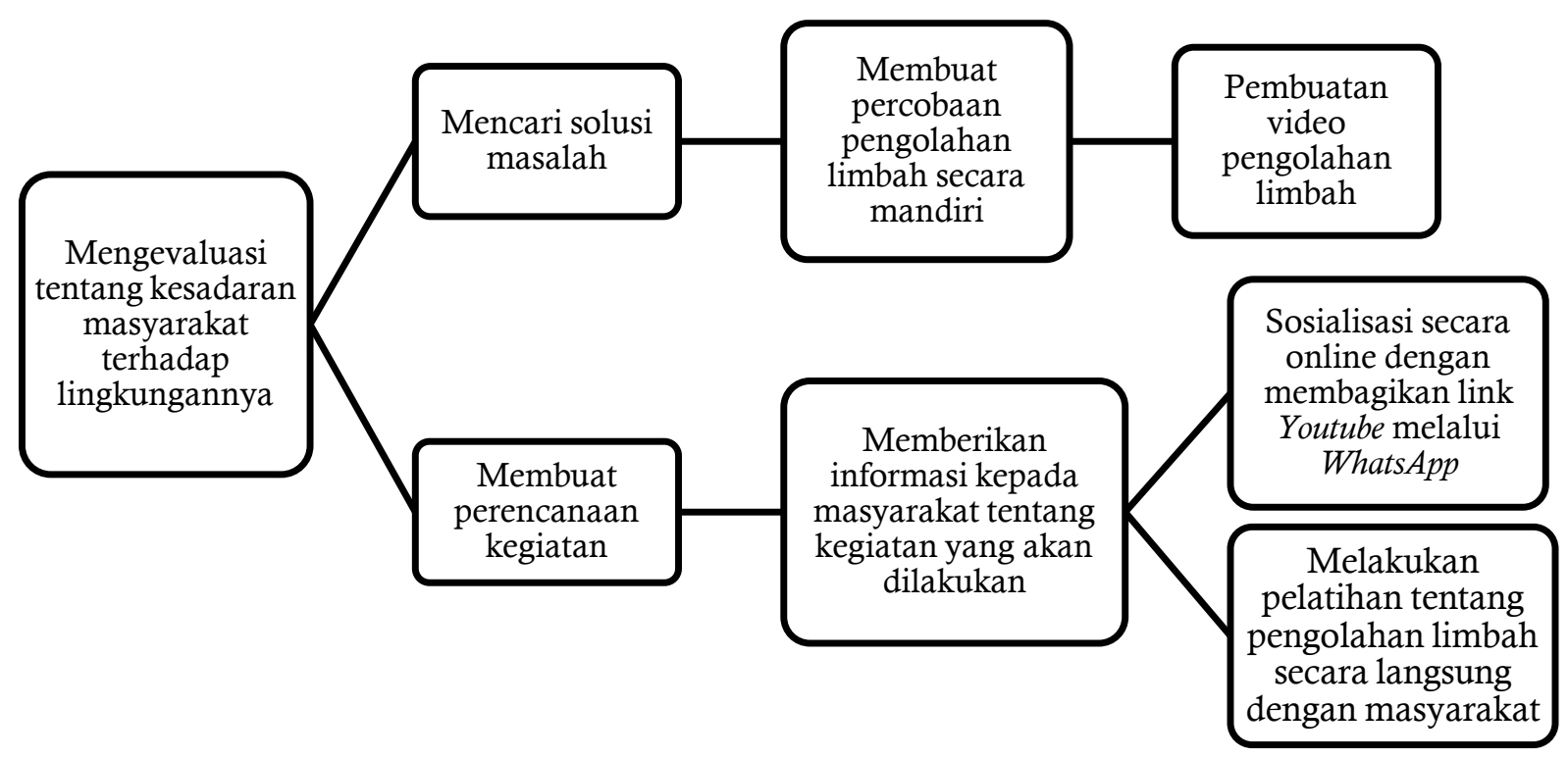

Gambar 1. Alur Metode Pelaksanaan Gerakan Sadar Lingkungan Melalui Sosialisasi Dan Pelatihan Pengelolaan Limbah Cair Rumah Tangga

\section{Hasil dan Pembahasan}

Sosialisasi dan praktik dengan tema pengolahan limbah cair rumah tangga di Dukuh Jongso Desa Wotan yang bekerjasama dengan masyarakat. Pelatihan secara langsung ini dilakukan oleh pengabdi dan tiga orang peserta dari daerah tersebut, sedangkan sosialisasi secara online dilakukan dengan ibu Pemberdayaan Kesejahteraan Keluarga (PKK) dan masyarakat umum. Pada kegiatan ini ternyata peserta antusias mengikuti pelatihan pengolahan limbah cair rumah tangga selain itu masyarakat juga tertarik untuk melihat secara online melalui Youtube pengolahan limbah cair rumah tangga. Hal ini dikarenakan belum pernah ada masyarakat yang mencoba untuk mengolah limbah cair di Dukuh Jongso Desa Wotan dan pengetahuan masyarakat sekitar yang masih minim dan kurangnya kepedulian masyarakat mengenai lingkungan sekitar. Adapun kendala yang dihadapi berupa minimnya pengetahuan tentang alat dan bahan yang digunakan dalam pengolahan limbah cair.

Sosialisasi secara online dilakukan dengan tujuan agar dapat dijangkau oleh masyarakat umum yang tidak menghendaki untuk diadakan perkumpulan. Selain itu juga untuk mencoba apakah limbah rumah tangga dapat diolah menggunakan tawas. Sosialisasi secara online ini dilakukan dengan membuat suatu video, dimana dalam video diberikan penjelasan tentang limbah yang berada di lingkungan sekitar dan tentang kegunaan tawas sebagai bahan pengolah limbah. Hasil video dibagikan melalui grup PKK dan untuk masyarakat umum dalam bentuk link Youtube. Dimana dengan adanya kegiatan ini masyarakat merasa berterima kasih karena merasa mendapatkan pengetahuan tentang sadar akan lingkungan sekitar terutama tentang pengolahan limbah cair rumah tangga. Hal tersebut juga karena sebagian besar masyarakat sekitar mempunyai tingkat pendidikan yang relatif masih rendah sehingga kurang akan pengetahuan. Selain itu berdasarkan hasil evaluasi bahwa masyarakat merasa sangat antusias dengan adanya cara pengolahan limbah yang sederhana dan terjangkau oleh semua kalangan.

Sosialisasi pengolahan limbah cair rumah tangga secara online ini dilakukan secara audio visual, dimana materi dapat disampaikan dengan menggunakan alat elektronik untuk menyajikan pesan-pesan audio dan visual. Kelebihan media audio-visual ini diantaranya yaitu dapat memperjelas penyajian pesan, mengatasi keterbatasan ruang, dan berperan dalam penyampaian pelatihan atau tutorial khususnya kepada masyarakat tentang pengolahan limbah cair rumah tangga (Purwono et al., 2014). 


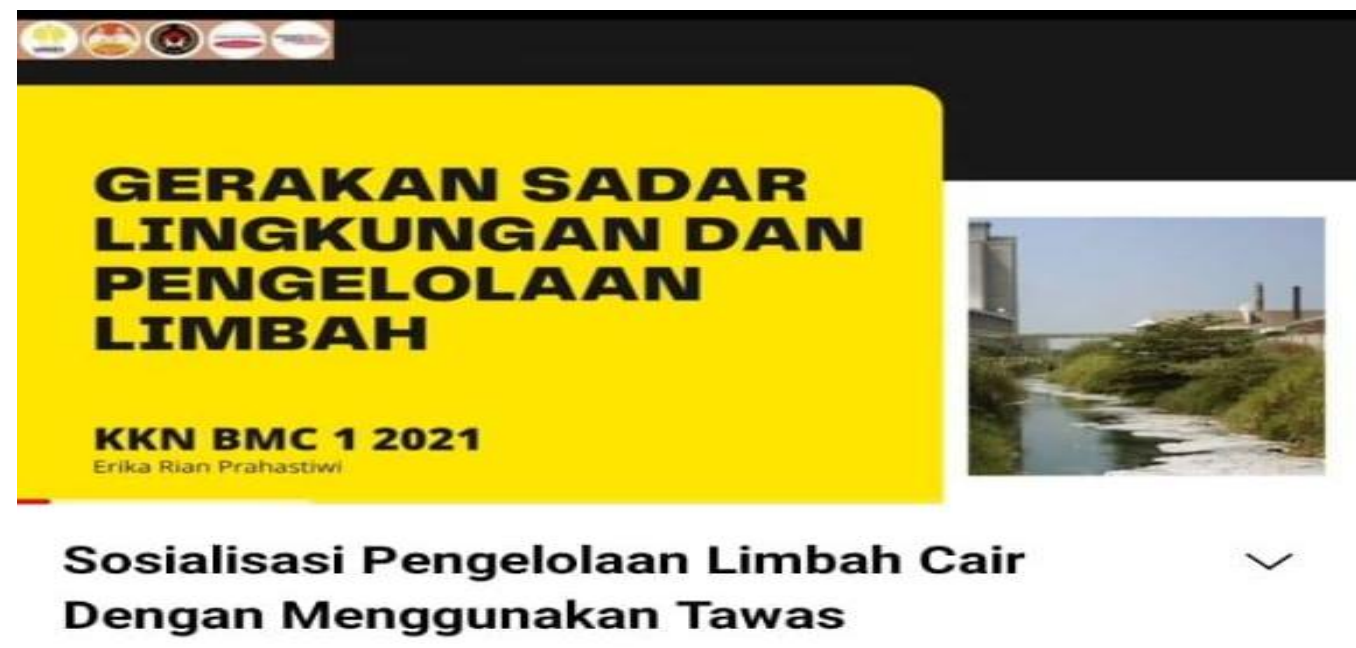

$15 \times$ ditonton 3 hari yang lalu

Gambar 1. Sosialisasi Pengolahan Limbah Cair Rumah Tangga Melalui Youtube.

Berdasarkan data yang dihasilkan dari respon peserta yang mengikuti bahwa $73 \%$ peserta sangat antusias dengan mencoba bertanya dan memahami apa yang disampaikan melalui sosialisasi pengolahan limbah cair rumah tangga secara audio-visual melalui Youtube. Berikut data hasil respon dari peserta :

Tabel 1. Respon Peserta Sosialisasi Online Pengolahan Limbah Cair Rumah Tangga.

\begin{tabular}{ccc}
\hline $\mathrm{N}$ & Cukup Antusias & Sangat Antusias \\
\hline 11 & 3 & 8 \\
\hline
\end{tabular}

Selain itu juga diadakan pelatihan secara langsung pengolahan limbah cair rumah tangga dengan tawas dimana peserta diberikan pengetahuan tentang bahaya limbah apabila tidak diolah, manfaat pengolahan limbah, fungsi dan bahan yang digunakan, dan tahapan yang dilakukan dalam pengolahan limbah cair rumah tangga. Pelatihan dilakukan dengan memperhatikan protokol kesehatan. Selain itu, masyarakat juga diberikan masukan kegiatan aktivitas yang dapat dilakukan selama dirumah saja akibat pandemi covid-19 salah satunya dengan gerakan sadar lingkungan melalui pengolahan limbah cair rumah tangga. Pengolahan limbah ini sampel diambil dari salah satu selokan di depan rumah warga yang ditaruh dalam wadah kemudian dituangkan dalam gelas untuk dilakukan pengolahan. Bahan utama yang diguanakan dalam pengolahan ini yaitu tawas yang berbentuk bongkahan, dimana tawas merupakan koagulan yang mampu mengendapkan zat-zat organik yang relatif cepat (Nurlina et al., 2015). Selain itu, tawas juga banyak ditemukan dipasaran dengan harga yang terjangkau dibandingkan dengan bahan lainnya. Pada tahapan pengolahan limbah sebaiknya sebelum bongkahan tawas direaksikan dilarutkan terlebih dahulu, hal tersebut untuk mempercepat proses pengikatan kotoran dalam air sampel limbah. Dari hasil sampel terlihat air sangat jernih setelah satu jam direaksikan.

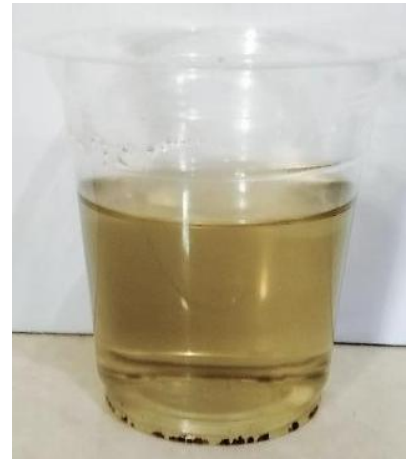

Sebelum

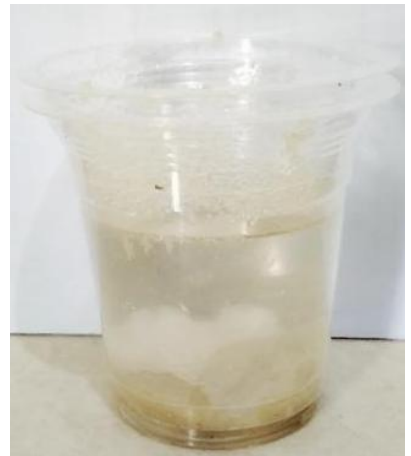

Sesudah

Gambar 2. Limbah Cair Rumah Tangga Sebelum dan Sesudah Diolah 


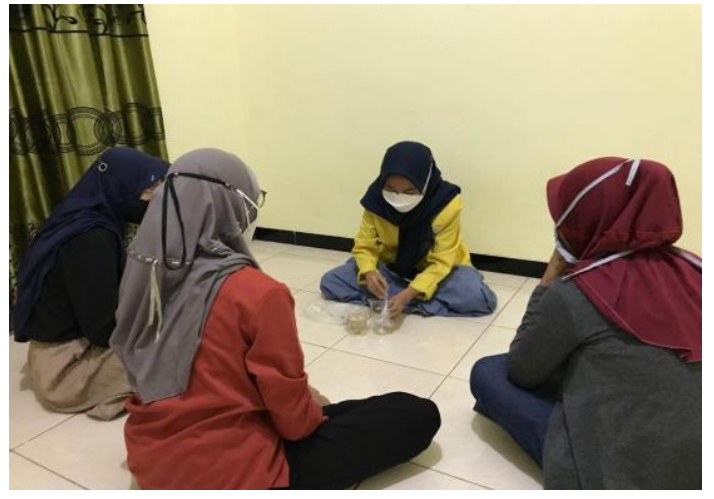

Gambar 3. Pelatihan Pengolahan Limbah Cair Rumah Tangga

Pelatihan merupakan proses belajar dimana juga terdapat kebutuhan menyebarkan pengetahuan, sehingga peserta pelatihan dapat menjadi pelatih juga bagi sekitarnya. Dalam pengelolaan limbah secara langsung menggunakan media pembelajaran serbaneka. Serbaneka merupakan suatu media yang disesuaikan dengan potensi pada suatu daerah, disekitar lokasi ataupun dimasyarakat yang dapat dimanfaatkan sebagai media pengajar. Pada pelatihan pengelolaan limbah cair di Desa Jongso digunakan media serbaneka dengan mengambil sampel limbah yang ada di selokan salah satu rumah warga. Dalam pelatihan hal yang perlu diperhatikan adalah tindakan korektif untuk peserta guna meningkatkan produktivitas, keterampilan dan pengembangan program pelatihan. Dengan adanya pelatihan dapat memberikan peningkatan kapasitas peserta pelatihan dalam pengetahuan (knowledge), ketrampilan (skill), dan sikap (attitude) secara menyeluruh (Wardhani et al., 2015). Pengetahuan dari pelatihan ini yaitu peserta dapat mengetahui bagaimana cara penanganan limbah dengan bahan yang sederhana (bongkahan tawas) dengan harga terjangkau, keterampilan pada pelatihan ini yaitu peserta dapat mencoba untuk mempraktikan cara pengolahan limbah dengan tahapan yang benar, dan sikap masyarakat yang dapat lebih perduli terhadap lingkungan sekitarnya. Salah satu pengukuran efektivitas penilaian pelatihan yaitu dengan respon peserta dimana berdasarkan hasil pelatihan menunjukkan bahwa peserta sangat antusias dengan kegiatan pelatihan ini.

\section{Simpulan}

Kegiatan pengabdian kepada masyarakat melalui sosialisasi secara online Youtube dan pelatihan secara langsung di Dukuh Jongso Desa Wotan Kecamatan Sukolilo Kabupaten Pati terlaksana dalam upaya mengedukasi terutama tentang kesadaran masyarakat terhadap lingkungan sekitar hal tersebut dapat dilihat dari antusias peserta sosialisasi dan pelatihan. Pengabdian yang dilakukan telah mencapai tujuan yang diharapkan yaitu peserta dapat meningkatkan pengetahuan dan keterampilan dalam penanganan lingkungan sekitar. Pelatihan ini diharapkan dapat disalurkan oleh peserta dengan memberikan contoh kepada masyarakat sekitarnya agar pelatihan dapat dijangkau oleh masyarakat luas.

\section{Referensi}

Dahruji, Wilianarti, pipit festy, \& Hendarto, T. (2017). Aksiologiya: Jurnal Pengabdian Kepada Masyarakat Studi Pengolahan Limbah Usaha Mandiri Rumah Tangga dan Dampak Bagi Kesehatan di Wilayah Kenjeran. Pengabdian Kepada Masyarakat, 1(1), 36-44.

Kusumawardhani, A. A., Wardhani, E., \& Halomoan, N. (2017). Penentuan Sistem Pengelolaan Air Limbah Domestik Di. 23, 9-13.

Nababan, D., Sitorus, M. E. J., Brahmana, N. E. B., \& Silitonga, E. M. (2020). Kemampuan Biofilter Anaerob Berdasarkan Jenis Media dalam Pengolahan Air Limbah Domestik Tahun 2016. Jurnal Riset Hesti Medan Akper Kesdam I/BB Medan, 4(2), 105.

Nasihah, M., Saraswati, A. A., \& Najah, S. (2018). Uji Pengolahan Limbah Cair Domestik Melalui Metode Koagulasi-Flokulasi dan Fitoremidiasi dengan Tanaman Kayu Apu (Pistia stratiotes L.). Jurnal Enviscience, 2(2), 76.

Nilasari, E., Faizal, M., \& Suheryanto, S. (2016). Pengolahan Air Limbah Rumah Tangga dengan Menggunakan Proses Gabungan Saringan Bertingkat dan Bioremediasi Eceng Gondok (Eichornia Crassipes), (Studi Kasus di Perumahan Griya Mitra 2, Palembang). Jurnal Penelitian Sains, 18(1), 168089. 
Nugti, M. A., Mei, S., Cahyani, D., Latifah, L., \& Sugiharto, A. (2020). Uji Efektifitas Koagulan Kapur ( $\mathrm{CaO}$ ), Ferri Klorida ( $\mathrm{FeCl} 3$ ), Tawas ( $\mathrm{Al} 2$ ( $\mathrm{SO} 4$ ) 3 ) Terhadap Penurunan Kadar PO4 dan COD Pada Limbah Cair Domestik ( Laundry ) Dengan Metode Koagulasi. University Research Colloquium, 345-348.

Nurlina, Zahara, T. A., Gusrizal, \& Kartika, I. D. (2015). Effective Use of Alum and Activated Carbon in Tofu Waste Water Treatment. Prosiding SEMIRATA 2015, 690-699.

Purwono, J. dkk. (2018). Penggunaan Media Audio-Visual pada Mata Pelajaran Ilmu Pengetahuan Alam di Sekolah Menengah Pertama Negeri 1 Pacitan. Jurnal Teknologi Pendidikan Dan Pembelajaran, 2(2), 127-144.

Ratnamulyani, Ike Atikah., \& Beddy Iriawan Maksudi. (2018). Peran Media Sosial Dalam Peningkatan Partisipasi Pemilih Pemula Dikalangan Pelajar Di Kabupaten Bogor. Jurnal Ilmu Sosial dan Humaniora, 20(02), 154-161.

Tuwu, D. (2020). Kebijakan Pemerintah Dalam Penanganan Pandemi Covid-19. Journal Publicuho, 3(2), 267.

Waluyo, L. (2017). Bioremediasi limbah cair rumah tangga dengan produk formula konsorsium pengurai limbah. Seminar Nasional Dan Gelar Produk, 99-107.

Wardhani, C. H., Sumartono, S., \& Makmur, M. (2015). Manajemen Penyelenggaraan Program Pelatihan Masyarakat (Studi di Balai Besar Pemberdayaan Masyarakat dan Desa Kementerian Dalam Negeri di Malang). Wacana, Jurnal Sosial Dan Humaniora, 18(01), 21-30.

Weol, D. H. (2015). Pengaruh Lingkungan Kerja, Pelatihan Dan Penempatan Terhadap Kinerja Pegawai Di Dinas Pendidikan Nasional Provinsi Sulawesi Utara. Jurnal Berkala Ilmiah Efisiensi, 15(5), 598609. 